\title{
O PAPEL DA VIGILÂNCIA EM SAÚDE DO TRABALHADOR NA 14a COORDENADORIA REGIONAL DE SAÚDE DO ESTADO DO RIO GRANDE DO SUL
}

\author{
THE ROLE OF WORKER'S HEALTH SURVEILLANCE IN THE 14 TH \\ REGIONAL HEALTH COORDINATION OF THE STATE OF RIO GRANDE \\ DOSUL
}

Rodrigo Pedrolo ${ }^{1}$

${ }^{1} 14^{a}$ Coordenadoria Regional de Saúde, Santa Rosa, Rio Grande do Sul, Brasil.

\section{RESUMO}

Objetivo: descrever o papel da vigilância em saúde do trabalhador da $14^{a}$ Coordenadoria Regional de Saúde. Metodologia: estudo descritivo na modalidade relato de experiência através de análise qualitativa da vivência da vigilância em saúde do trabalhador da $14^{\text {a }}$ Coordenadoria Regional de Saúde. Resultados: foram descritos as principais atividades e funções desta vigilância, como: realização de atividades educativas e de conscientização as vigilâncias em saúde do trabalhador municipais, serviços regulados e escolas; auxílio aos municípios nas investigaçóes de óbitos relacionados ao trabalho, bem como validação dos mesmos no sistema de informação; retaguarda aos profissionais de saúde sobre como caracterizar e notificar os agravos e acompanhar o desenvolvimento das notificaçôes nos sistemas de notificação; realização de inspeçôes sanitárias in loco para constatação das condiçôes laborais e saúde dos trabalhadores. Consideraçóes Finais: as atividades da vigilância em saúde do trabalhador vão desde questôes educativas até situaçóes fiscalizatórias para que se possam traças estratégias de conscientização, prevenção e preservação da saúde dos trabalhadores.

Descritores: Vigilância em Saúde do Trabalhador; Atividades educativas; Investigação de óbitos; Notificação de agravos; Inspeção sanitária.

\section{ABSTRACT}

Objective: this study aims to describe the role of the 14th Regional Health Coordination (14th CRS) workers' health surveillance. Methodology: descriptive study based on experience report through qualitative analysis of the workers' health surveillance experience from 14th CRS. Results: main activities and functions of this surveillance were described, such as: educational activities and awareness-raising for municipal workers' health surveillance, regulated services and schools; assistance to municipalities in investigating work-related deaths, as well as validating them in the information system; assistance for health professionals on how to characterize and notify diseases and monitor 
the notifications in the notification systems; carrying out health inspections to verify the working conditions and workers' health. Final Considerations: activities of workers' health surveillance range from educational issues to health inspections so that strategies for raising awareness, preventing and preserving workers' health can be drawn up.

Descriptors: Workers' Health Surveillance; educational activities; work-related death investigation; notifiable deseases; health inspection.

\section{INTRODUÇÃO}

A Portaria no 1378/2013 determina que as açôes de Vigilância em Saúde devem abranger toda a população brasileira e envolver práticas e processos de trabalho voltados para, dentre outras, a vigilância em saúde do trabalhador ${ }^{1}$. No Estado do Rio Grande do Sul, o processo de formação da Vigilância em Saúde é realizado pelas áreas ambiental, epidemiológica, sanitária e saúde do trabalho. Para isso, a Lei Federal no 8080/90 determina por saúde do trabalhador:

[...] um conjunto de atividades que se destina, através das açôes de vigilância epidemiológica e vigilância sanitária, à promoção e proteção da saúde dos trabalhadores, assim como visa à recuperação e reabilitação da saúde dos trabalhadores submetidos aos riscos e agravos advindos das condiçóes de trabalho $[\ldots]^{2}$.

Igualmente a Portaria no 1363/2014 que institui a Política Estadual de Saúde do Trabalhador e da Trabalhadora no Rio Grande do Sul, possui como objetivo:

[...] definir os princípios, as diretrizes e as estratégias a serem observados pelas esferas estadual e municipal de gestão do Sistema Único de Saúde (SUS), para o desenvolvimento da atenção integral à saúde do trabalhador e da trabalhadora, com ênfase na vigilância, visando a promoção e a proteção, a recuperação e a reabilitação da saúde do trabalhador e da trabalhadora e a reduçấo da morbimortalidade decorrente dos processos produtivos ${ }^{3}$.

Isso demonstra o grande papel dos entes federativos em desenvolverem práticas e políticas públicas para a caracterização e prevenção das doenças e acidentes relacionados ao trabalho, envolvendo o fortalecimento das atividades educativas, investigaçóes de óbitos relacionados ao trabalho, sistemas de notificaçôes de agravos e inspeçóes sanitárias in loco.

Logo, este artigo possui como objetivo descrever o papel da vigilância em saúde do trabalhador (VISAT) da 14 a Coordenadoria Regional de Saúde (CRS) nos 22 municípios que a compõe e sua área de atuação.

\section{METODOLOGIA}

Trata-se de estudo descritivo através de análise qualitativa da vivência da VISAT da $14^{\mathrm{a}}$ CRS no período de abril de 2018 até janeiro de 2021, levando em consideração as normatizaçóes vigentes. 


\section{RESULTADOS E DISCUSSÃO}

Para a prestação de serviços públicos aos 22 municípios pertencentes a $14^{\mathrm{a}} \mathrm{CRS}$, a VISAT possui as seguintes funçôes e atividades:

\section{Atividades Educativas}

Como premissa está a realização de atividades educativas e de conscientização as VISATs municipais, serviços regulados e escolas técnicas. São realizadas palestras/reunióes com as equipes de saúde municipais envolvendo a atualização das normatizaçôes, importância da realização das notificaçôes dos agravos e investigação dos óbitos relacionados ao trabalho. Também, são sanadas dúvidas dos serviços regulados referentes a aplicabilidade das normatizaçóes vigentes na área da saúde do trabalhador. Da mesma forma, realização de palestras em escolas técnicas para conscientização dos futuros profissionais na prevenção de acidentes e adoecimentos no trabalho, como também o processo de realização das notificações dos agravos.

\section{Investigação de óbitos relacionados ao trabalho}

De acordo com o Centro Estadual de Vigilância em Saúdo do Rio Grande do Sul (CEVS):

A expressão de maior gravidade do acidente de trabalho é a morte do trabalhador. Existe impacto social na família e na comunidade, e impacto financeiro em toda a sociedade. Os óbitos de trabalhadores são passíveis de prevenção, e são indicadores de condiçóes de risco no trabalho que precisam ser eliminadas. A investigação de cada um deles impóe-se a fim de que se corrijam as condiçôes que os ocasionaram e seja evitado ocorrência de novos casos ${ }^{4}$.

Para isso, compete ao município onde ocorreu o acidente realizar a investigação, conforme Figura 01 - fluxograma para investigaçáo de óbitos relacionados ao trabalho, e preencher o formulário de investigação de óbito no Sistema de Informação em Saúde do Trabalhador (SIST). O Protocolo Técnico de Investigação de Óbito Relacionado ao Trabalho no Rio Grande do Sul (2020) determina que:

[...] a investigação destes óbitos pode requerer a cooperação técnica entre os municípios do local de ocorrência do acidente, de residência do(a) trabalhador(a), do local de trabalho, do local de atendimento prestado (urgência/emergência, Instituto Médico Legal-IML, etc) e/ou outros 5 . 
Figura 01: Fluxograma para investigação de óbitos relacionados ao trabalho

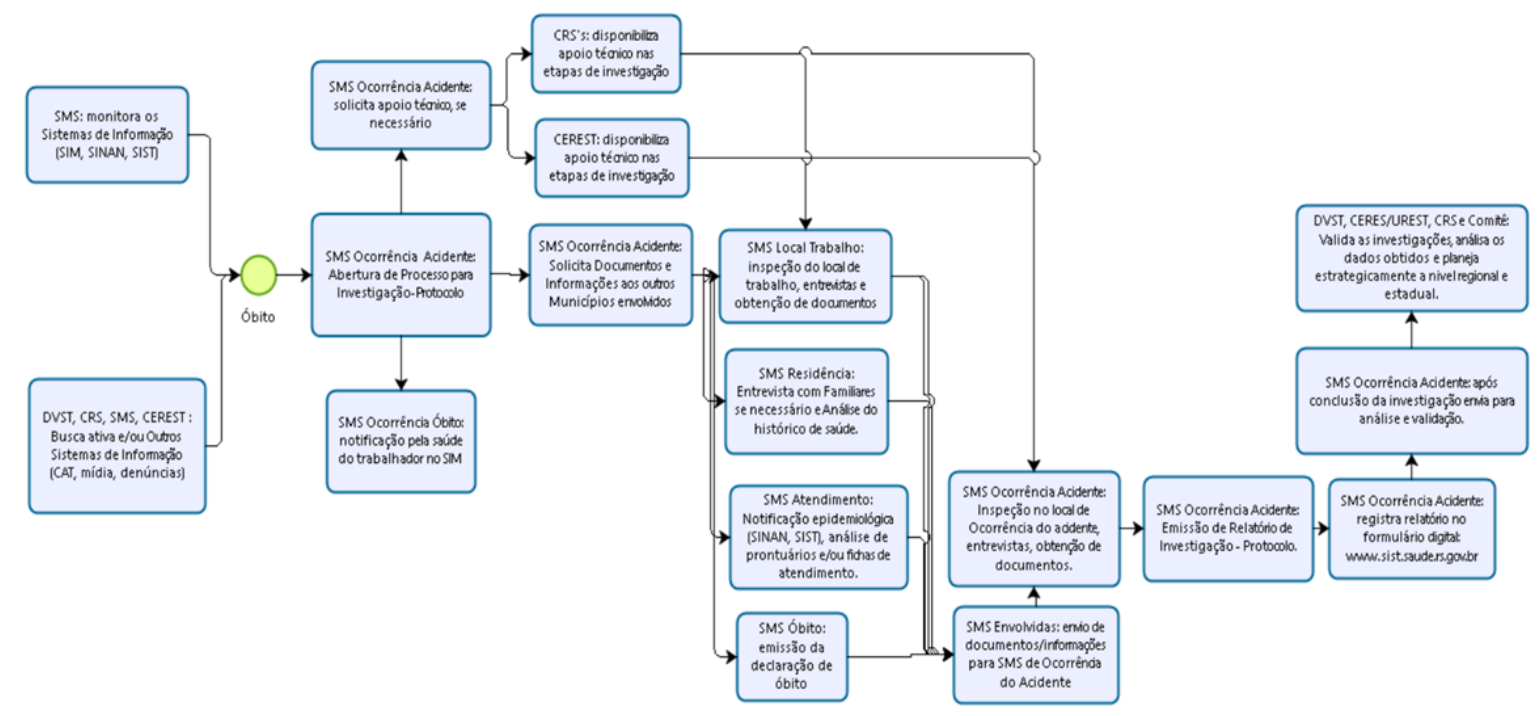

Fonte: Protocolo Técnico de Investigação de Óbito Relacionado ao Trabalho no Rio Grande do Sul (2020)

Essa investigação compóem o indicador RS 03 - Proporção de óbitos por acidentes de trabalho investigado, onde os municípios necessitam investigar 100\% dos óbitos relacionados ao trabalho ocorridos em seu território. Para alcançar esse indicador o município que esteja realizando a investigaçáo do óbito por acidente de trabalho necessita analisar documentos sobre o fato, ir a campo para conhecer os fatores que ocasionaram o acidente, bem como sugerir melhorias para que o evento não venha a ocorrer novamente. O papel da VISAT da $14^{\text {a }}$ CRS é auxiliar os municípios nas dúvidas dessas investigaçôes, bem como realizar a validação das mesmas no SIST.

\section{Agravos relacionados ao trabalho (acidentes e doenças)}

Todo agravo relacionado ao trabalho deve ser notificado no Sistema de Informação de Agravos de Notificação (SINAN) ou SIST conforme a normatização vigente. Cada município necessita possuir, no mínimo, um representante para realizar a notificação e cadastramento dos agravos nos sistemas.

Essas notificações compóem o indicador RS 04 - Taxa de notificação de agravos (acidentes e doenças) relacionadas ao trabalho, onde os municípios necessitam alcançar a taxa pactuada de 40,00. Ou seja, os municípios precisam, no mínimo, realizar 40 notificaçóes relacionadas ao trabalho para cada 10.000 habitantes de seu território. Conforme o manual do processo de notificação de doenças e agravos relacionados ao trabalho da Secretaria Estadual da Saúde do Estado do Rio Grande do Sul (2000), o indicador desse processo é a taxa de notificação (Número de notificaçóes por 10.000 habitantes $)^{6}$, calculado da seguinte forma: 
Taxa $=\underline{(\text { Número de notificaçôes de agravos no SIST e SINAN) } \times 10.000}$

$$
\text { População }
$$

Conforme a Nota Técnica de Orientações para Notificaçôes de Agravos no 01/2020 DVST/CEVS/SES sabe-se que são de notificação compulsório no SINAN:

todos os acidentes de trabalho, acidentes de trabalho com exposição a material biológico, intoxicação exógena relacionada ao trabalho, por substâncias químicas, incluindo agrotóxicos, gases tóxicos e metais pesados, violência doméstica e/ou outras violência incluindo trabalho infantil, câncer relacionado ao trabalho, dermatoses ocupacionais, lesōes por esforço repetitivo/distúrbios relacionados ao trabalho (LER/DORT), perda auditiva induzida por ruído (PAIR) relacionada ao trabalho, pneumoconioses relacionadas ao trabalho e transtornos mentais relacionados ao trabalho ${ }^{7}$.

Aquelas doenças relacionadas ao trabalho que não sejam de notificação compulsória no SINAN devem ser notificadas no SIST.

A VISAT da $14^{\text {a }}$ CRS atua como reta guarda aos profissionais de saúde sobre como caracterizar e notificar os agravos e acompanhar o desenvolvimento das notificaçóes nos sistemas de informação. Da mesma forma a VISAT da $14^{\mathrm{a}} \mathrm{CRS}$ realiza reunióes com secretários municipais de saúde e os representantes das VISATs municipais para relatar a importância da realização das notificaçôes dos agravos relacionados ao trabalho, auxílio nas dúvidas sobre os sistemas de informação e interpretação das normatizações vigentes para que os municípios consigam atingir a meta pactuada.

\section{Inspeçóes sanitárias em saúde do trabalhador}

Igualmente, a VISAT da $14^{\mathrm{a}}$ CRS realiza inspeçóes sanitárias nos seguintes estabelecimentos regulados pelo estado como: Hospitais, Pronto Atendimentos de Urgência, Hemocentro, Laboratórios de Análises Clínicas, Clínica Oncológica, Indústrias saneantes (produtos químicos), Indústrias de cosméticos, Indústrias de alimentos, Indústria e embaladores de chás e especiarias e Indústria de produto para saúde. O objetivo é realizar verificação in loco das condiçôes laborais e de saúde dos trabalhadores através da aplicabilidade das normatizaçôes da saúde, em especial as Resoluçôes da Diretoria Colegiada (RDC). Essas inspeçôes são necessárias, pois, contribuem para o processo de liberação do alvará sanitário dos estabelecimentos (realizado pela vigilância sanitária).

Do mesmo modo, são realizadas inspeçôes in loco quando ocorrem denúncias, conforme demanda.

Da mesma forma a VISAT da $14^{\text {a }}$ CRS realiza inspeçóes in loco através de forças tarefas com o Ministério Público do Trabalho e Centro de Referência Regional em Saúde do Trabalhador (CEREST) de Santa Rosa para constatação das condiçóes laborais dos trabalhadores. Já ocorreram essas vistorias em hospitais e metalúrgicas. 


\section{CONCLUSÓES}

Como pôde ser observado, a VISAT da $14^{\text {a }}$ CRS atua de forma ativa na comunidade e nos 22 municípios de sua área de abrangência. Isso propicia o fortalecimento de questóes educativas até situaçôes fiscalizatórias.

$\mathrm{Na}$ área educativa incentiva-se os futuros profissionais a possuírem a preocupação da prevenção do adoecimento e acidente no trabalho, como também, o papel da VISAT na área de abrangência.

Outrossim, através da realização das notificaçôes dos agravos (acidentes e doenças) relacionados ao trabalho, consegue-se compreender do que se acidenta e adoece os trabalhadores, para que se possam traças estratégias de conscientização e prevenção. $\mathrm{O}$ intuito é conhecer essa problemática nos territórios municipais, para que os entes federativos consigam traçar políticas públicas em prol da saúde e segurança dos trabalhadores.

Igualmente, investigar $100 \%$ dos óbitos relacionados ao trabalho ocorridos nos municípios da $14^{\mathrm{a}} \mathrm{CRS}$, propicia identificar e compreender quais situaçóes e atividades acarretam na morte do trabalhador. Isso proporcionará o desenvolvimento de mecanismos, principalmente de conscientização, para que os óbitos não ocorram novamente no território do nosso estado.

Por fim, realizar vistorias in loco, através da aplicabilidade da normatização vigente na área da saúde do trabalhador, acarreta na constatação das condições laborais para que se possam garantir o trabalho seguro e a preservação da saúde dos trabalhadores.

\section{REFERÊNCIAS}

1. Ministério da Saúde. Portaria no 1378 de 9 de julho de 2013. Acesso em: 05 jan 2021. Disponível em:http://bvsms.saude.gov.br/bvs/saudelegis/gm/2013/ prt1378_09_07_2013.html.

2. Brasil. Presidência da República. Lei no 8080 de 19 de setembro de 1990. Brasília. Acesso em: 22 dez 2020. Disponível em: http://www.planalto.gov.br/ccivil_03/leis/ L8080.htm.

3. Secretaria da Saúde do Rio Grande do Sul. Centro Estadual de Vigilância em Saúde do RS. Portaria no 1363 de 24 de dezembro de 2014. Acesso em: 23 dez 2020. Disponível em: https:/www.cevs.rs.gov.br/politica-estadual-de-saude-do-trabalhador-eda-trabalhadora.

4. Secretaria da Saúde do Rio Grande do Sul. Centro Estadual de Vigilância em Saúde do RS. Vigilância em Saúde - Investigação de Óbitos Relacionados ao Trabalho. Acesso em: 05 jan 2021. Disponível em: https://www.cevs.rs.gov.br/vigilancia-investigacao-deobitos. 
5. Secretaria da Saúde do Rio Grande do Sul. Centro Estadual de Vigilância em Saúde do RS. Protocolo Técnico de Investigaçáo de Óbito Relacionado ao Trabalho no Rio Grande do Sul. Versão 2020.

6. Secretaria da Saúde do Rio Grande do Sul. Manual do Processo de Notificação de Doenças e Agravos Relacionados ao Trabalho. Versão 1.0. 2020.

7. Estado do Rio Grande do Sul. Centro Estadual de Vigilância em Saúde do RS. Nota Técnica de Orientação para Notificação de Agravos no 01/2020 DVST/CEVS/ SES. Acesso em: 05 jan 2021. Disponível em: https:/www.cevs.rs.gov.br/upload/ arquivos/202010/26142005-nota-tecnica-01-2020-notificacao-de-agravos.pdf.

Autor Correspondente: Rodrigo Pedrolo E-mail: rodrigo-pedrolo@saude.rs.gov.br Recebido em: 2021-01-06 Aprovado em: 2021-09-13 